\title{
Where next in flood risk management? A personal view on research needs and directions
}

\author{
P. G. Samuels ${ }^{1}$ \\ ${ }^{1}$ HR Wallingford, Howbery Park, Wallingford, OXON, OX10 8BA, UK
}

Published in the proceedings of the 2nd European Conference on Flood Risk Management, FLOODrisk2012, Rotterdam, The Netherlands, 19-23 November 2013

\section{Abstract}

Over the past three decades or more, much research and development effort and resource has been devoted in national and international programmes to reduce the impact of floods and flooding. The way in which this research has been commissioned and organised has changed over the decades in response to the evolution of policy from the technical focus of flood defence to the multidisciplinary character of flood risk management. This paper begins with a look back at some illustrative programmes and approaches (drawn from the UK and the EC) before moving onto a personal view of the drivers of future flood risk and its management and the priorities for generation of further knowledge and understanding. After identifying the importance to R\&D of the availability of and access to reliable data, I discuss research needs in support of three general areas: firstly on long-term planning and options assessment, secondly on management of flood emergencies and thirdly on exploring adaptation and resilience to floods. Finally, it is essential that, whatever research is done in the future, there is a clear plan and commitment for the research outcomes to be brought into practice.

\section{Introduction}

Over the past three decades or more, much research and development effort and resource has been devoted in national and international programmes to reduce the impact of floods and flooding. Research has been undertaken in many contexts - basic research for PhD theses, Government support to national institutes, strategic national programmes of applied research and development, and international programmes such as the Framework Programmes funded by the European Union.

The OECD "Frascati Manual" (Organisation for Economic Co-operation and Development 1993) provides an internationally accepted categorisation of research and development activities which I shall use in this paper. The following definitions come from the Second Chapter of the Frascati Manual.

"Research and experimental development $(R \& D)$ comprise creative work undertaken on a systematic basis in order to increase the stock of knowledge, including knowledge of man, culture and society, and the use of this stock of knowledge to devise new applications.

$R \& D$ is a term covering three activities: basic research, applied research, and experimental development 
- Basic research is experimental or theoretical work undertaken primarily to acquire new knowledge of the underlying foundation of phenomena and observable facts, without any particular application or use in view.

- Applied research is also original investigation undertaken to acquire new knowledge. It is, however, directed primarily towards a specific practical aim or objective.

- Experimental development is systematic work, drawing on existing knowledge gained from research, and/or practical experience, that is directed to producing new materials, products or devices, to installing new processes, systems and services, or to improving substantially those already produced or installed."

In terms of flood risk management, research and development has supported a policy change from flood protection and flood defence to the broader objective of flood risk management (Klijn et al. 2008b). Flood risk is an evaluation of the combination of the probability of flooding and the adverse consequences that ensues. Thus the concept of risk is entirely a human construct through the values (monetary or not) we place upon the consequences of flooding. It is now widely recognised that absolute protection from flooding cannot be achieved and the societal goal is for the management of flood risks at an "acceptable" level. Flood risk management therefore has the character of a "wicked problem" (Rittel \& Webber 1973) in that flood risk is part of a broader environmental and social system, there are many potential solutions with no "true" or "false" answers and different stakeholders have differing (and potentially conflicting) views of the problem.

In the past much research addressed specific technical issues such as the assessment of the capacity of a flood channel, construction of computational hydrodynamic models, radar hydrology or economic consequences of floods. Such projects generate knowledge for design of defences, forecasting software, estimation of flood damage etc. Research and development on flood risk management however is broader; it may combine aspects of physical and social sciences depending upon what part of and interactions in the overall risk system are being investigated.

This paper presents a personal reflection on the processes and content of research and development on flooding issues and is based primarily upon my own experience of research funded in the UK and by the European Commission (EC).

\section{Where have we been?}

\subsection{Illustrative programmes and approaches}

\subsubsection{Flood research in the UK}

Within this section, few distinctions are made between the arrangements in the different countries (England, Scotland, Wales and Northern Ireland) although over the past decade administrative arrangements have changed with devolution of powers in the UK away from central government in London.

Historically the policy responsibility for floods lay with the former Ministry of Agriculture Fisheries and Food (MAFF) which maintained a commissioned programme of applied research which was informed by periodic reviews. Nationally eminent researchers led these reviews, with the most recent being those of Peter Ackers (Ministry of Agriculture Fisheries and Food, 1992)and Professor Edmund Penning-Rowsell (Ministry of Agriculture, Fisheries and Food 1999; Penning-Rowsell 2005). Over the past decade the research programme of MAFF, now reorganised into the Department for Environment, Food and Rural Affairs (Defra), has been integrated with that of the Environment Agency into a single Joint Programme managed by the Environment Agency. An outcome of the first of Penning-Rowsell's reports was a significant change in 
research organisation from disciplinary topics (rivers, coasts, meteorology, etc) into broader multi-disciplinary themes (policy, modelling, assets, risk, forecasting). The Environment Agency maintains a web portal to the results of this applied research and development programme.

In parallel with this Government-funded applied R\&D, the UK research Councils have funded basic research on flooding processes through both "responsive" mode grants originating from a researcher and as part of a managed or directed programme. The research on the Flood Channel Facility (FCF) set up by the Science and Engineering Research Council (SERC) in 1986 and continued by the Engineering and Physical Sciences Research Council (EPSRC) (Knight \& Sellin 1987) was undertaken as a series of responsive mode grants. The FCF research led to fundamental measurements of turbulence and understanding of capacity of natural channels (Shiono \& Knight 1991) which through supplementary development funded by the Environment Agency has now entered into engineering practice (Mc Gahey et al. 2008, Knight et al. 2010).

In 2004 the EPSRC let the contract for a large managed programme (Pender, 2006) to the Flood Risk Management Research Consortium (FRMRC) which received a second round of funding in 2008. This managed programme included both basic and applied research with some of the research activities supporting directly the work of the Environment Agency and other funders. Over 20 academic institutions collaborated on the FRMRC research and, in contrast to the FCF research, the work of the FRMRC has moved more rapidly into practice.

\subsubsection{The EC Framework Programmes}

The EC Framework Programmes have supported research on hydrological risks and flooding since the 1980 's. Much of the research commissioned in the collaborative projects falls in the Frascati categories of applied research or experimental development; 100 past and active projects were identified in 2003 in a project on the water resources technology and management course at the University of Birmingham (Ashton et al. 2003) ${ }^{1}$. These projects had been commissioned up to the Fifth Framework Programme (FP5). Since then, many more R\&D projects have been commissioned in FP6 and FP7 between 2004 and 2012; the results of some of these are presented at the current conference FLOODrisk 2012. In FP7, the European Research Council (ERC) makes grants to support individual researchers to pursue their frontier research (see, for example, FloodChange ${ }^{2}$ ). This is in contrast to collaborative projects under the "cooperative funding" approach in FP6 and FP7 where large international project teams are assembled such as for the FP6 Integrated Project FLOODsite ${ }^{3}$.

\subsubsection{The CRUE ERA-NET}

The EC Sixth Framework Programme (FP6) introduced the new "instrument" of an ERA-NET whose purpose was to support the structuring of a broader collaborative European Research Area with each network directed at a specific area of interest to Member States. Rather than funding research directly, the EC grant covered the additional costs of establishing the network of national research funders and establishing a mechanism for identifying, commissioning and reviewing research projects and programmes of interest to several or all the Member States participating in the ERA-NET. The CRUE network on flooding involved 12 EU Member States; it produced a database of recent research programmes and projects in the countries

\footnotetext{
${ }^{1}$ available at http://www.actif-ec.net/library/review EU flood_projects.pdf

2 http://www.hydro.tuwien.ac.at/forschung/erc-advanced-grant-2012-2017

${ }^{3}$ see www.floodsite.net
} 
involved in the network, prepared a common research vision, and commissioned two rounds of research projects. The project website ${ }^{4}$ provides public access to all the outputs.

\subsubsection{Ad-hoc International co-operation}

In addition to generic R\&D programmes, international collaboration takes place on specific issues of common interest. An important current collaboration for flood risk management is the production of the International Levee Handbook (ILH) by an international team from France, USA, UK, Ireland, the Netherlands and Germany.

In September 2008, organisations from these six countries expressed a desire in principle to participate in an international project in order to learn from one another's experiences and to share the effort to produce good practice guidance as the ILH. There were several drivers for the collaboration including the US National Committee on Levee Safety which was established by Congress in response to Hurricane Katrina, the European Floods Directive (EC, 2007), various policy developments in the countries involved and the knowledge from research.

When completed, the ILH will be a compendium of good practice, offering comprehensive guidance on the design, construction, maintenance and improvement of levees as well as describing the international state of the art on these matters. It is planned that the ILH will offer a decision support framework covering specific challenges during the life cycle of levees for competent engineers, rather than being a prescriptive decision making code of practice.

Further information on the ILH is included in the papers presented during the special conference session at FLOODrisk 2012 on the handbook, including the overview (Simm et al. 2012).

\subsection{Identification of research needs and programmes}

Much of the expenditure on flood risk management activities comes ultimately from taxation through national and local government sources. Hence in most countries there is public funding of relevant research to ensure that the expenditure on all flood risk management remains effective. The character of the research however will reflect the priorities of the funder, with basic research commissioned from research councils and more applied or site-specific research commissioned by the relevant executive agency (e.g. National Environment Agency, River Basin Authority, Government policy department, etc). Within EU, the European Commission prepares a Framework Programme for Research and Innovation (the Eighth Framework Programme starts in 2013) which addresses topics of pan-European concern (as opposed to those localised to one Member State).

The starting point is often the identification of some overarching needs, which form the backdrop for the formulation of more detailed programmes and projects. For example in the UK the research councils have identified a theme of "Living with Environmental Change" as being essential for the future. Flooding research fits within this as potentially flood risks will be influenced by changes to the climate and the land surface. In 2011, the NERC launched an extensive consultation on research needs to prepare a research programme. The UK Flood and Coastal Erosion Risk Management Research Strategy was published in January $2012^{5}$. The strategy identifies priority research topics in three themes: Understanding Risk, Managing Probability

\footnotetext{
${ }^{4}$ http://www.crue-eranet.net/

${ }^{5}$ http://www.Iwec.org.uk/activities/uk-first-flood-research-strategy
} 
and Managing Consequences of flooding. A Steering Group oversees the implementation of the strategy; it will review progress and will update the strategy as appropriate.

In England and Wales DEFRA and the Environment Agency have a joint research programme on flooding and coastal risk management; the current (2009) programme is described in the Programme Definition document available on the Environment Agency website ${ }^{6}$.

The research needs are identified primarily in consultation with the Environment Agency's flood risk management staff but refined with the assistance of Theme Advisory Groups (TAG), which include some external experts to give advice. The overall programme is moderated by a Joint Programme Board which again has external membership. The work commissioned is exclusively applied research and experimental development and covers topics of short and medium term need within DEFRA and the Environment Agency to improve their effectiveness. The research projects are managed within broad themes of Strategy and Policy Development, Modelling and Risk, Sustainable Asset Management, and Incident Management and Community Engagement.

The content of the EC Framework Programmes is developed within the Research Directorate of the European Commission with extensive consultation involving the other EC Directorates, the scientific community, and the national representatives of the Member States. The research programmes are developed at several levels starting with a broad definition of the whole framework programme's objectives covering research in all sectors. The programme is segmented by type of action and thematic content, with more detailed definition of specific topics for funding provided through competitive calls. The content of the detailed research is ratified before its publication and to be successful research projects address the topic of the call. Several research projects on urban, river and coastal flooding have been funded in different areas of the Seventh Framework Programme.

The CRUE research agenda was produced through discussions within the Network members and an invited workshop. The research agenda is part of the overall CRUE Vision 2015, which is to "provide a coordinated and comprehensive transnational evidence base on FRM (flood risk management) issues to underpin the work of key national and European policy-makers". The research agenda document is published on the CRUE website (see above); it identifies five strategic research areas:

1. Developing resilience and adapting to increasing flood risks: climate change and new developments;

2. Risk assessment and mapping;

3. Implementing trans-national strategies on flood event management and recovery;

4. Meeting the multifunctional demands on flood prevention and protection and their sustainable management; and

5. Addressing public knowledge of flood risk and enhancing awareness, perception and communications.

The projects commissioned in two research calls have now been completed. The first led to seven projects within the theme of "Risk assessment and risk management: Effectiveness and efficiency of non-structural flood risk management measures"; the second call led to seven projects on "Flood resilient communities managing the consequences of flooding". There is much in the CRUE research Agenda that remains to be tackled.

${ }^{6}$ http://evidence.environmentagency.gov.uk/FCERM/Libraries/FCERM Documents/200911 PDD Refresh v3 FINAL.sflb.ashx) 


\subsection{Reflection}

Although the summary above is illustrative rather than comprehensive, some tentative common threads are evident.

Historically, research projects often addressed specific technical issues relating to flood defence leading to the development of new models, methods and datasets which could be applied in the design and assessment of flood defence measures.

For more than two decades large research programmes on flood risk management have been developed through a process of consultation with the stakeholders - researchers, policy makers, executive agencies, operation authorities, etc. The focus of these programmes has been on applied research and experimental development. In addition, basic and applied academic research has continued with funding predominantly in national projects but more recently internationally through the ERC.

Much research is now commissioned through large multidisciplinary programmes at the national and the European level. These programmes usually contain several separate projects but sometimes they commission a "super" project which then internally has major themes. In the case of the EC Framework Research flood research forms a component of larger priorities such as natural hazards, information technology application or security.

Although the applied research and experimental development is directed at solving complex problems arising in practice, the transfer of the research outcomes through to implementation and uptake into flood risk management practice is often not included within the scope of the research. This leads to an extended time from research advance to the benefits being fully realised. However, the CRUE Research Agenda did recognise explicitly the need for an implementation plan for utilising the knowledge. This issue is part of the broader current debate on the Science Policy Interface (Quevauviller 2011) and is not addressed further in the remainder of this paper.

\section{Where should we go?}

\subsection{The big issues}

The Foresight Future Flooding project examined the drivers of future flood risk for the UK though a combination of quantitative methods and expert elicitation (Office of Science and Technology 2004). However, the analysis of the drivers highlights issues of broader application even though the balance between the factors will vary from one country to another. The highest rated drivers of future risk across all the linked climate and socio-economic scenarios included:

- Social impacts

- Infrastructure impacts

- Relative sea level rise

- Surges

- Precipitation

- Waves

- Coastal and river morphology 
The report also identified those drivers with the greatest uncertainty as being particular candidates for further research (see Office of Science and Technology 2004, Appendix D of Volume 2).

Although changes in the hydro-meteorological factors were identified as of importance, social impacts were the highest or near highest rated influence in all scenarios considered. This should not be unexpected as flood risk management has strong human dimensions through the evaluation of flood damages, perception of and reaction to risk, policy for, and organisation of flood risk management measures. The expert elicitation component of the original Foresight project has since been updated.

The methodology has also been applied elsewhere, for example, to the Taihu basin in China (Harvey et al. 2009). In the different social, physical and economic conditions of that basin a different set of factors was identified as being the most important for driving future flood risk.

In my view, the backdrop internationally to the future evolution of flood risks and their management is dominated by the influence of:

- Climate change, extremes in precipitation and storms, and sea level rise;

- Population growth and density and the evolution of demographic distribution;

- Landscape-scale changes in land-use both for inland and the coastal zone including,

- Location and growth of megacities

- Increased habitation on marginal land;

- Value and distribution of assets in the land that is exposed to flood hazards;

- Changing public attitudes to flooding and their resilience to flooding;

- Ageing flood defence assets and the legacy of under-investment in maintenance and renewal;

- Cascading impacts, for example:

- Destabilisation of soils causing mud and debris flows,

- Threats to other critical infrastructure such as power, water supply, sanitation and food distribution networks,

- Internationally significant manufacturing and commercial centres.

In addition flood risk management practice needs to respond to organisational and governance issues such as:

- Changes in legislation and in Europe the interaction of the Floods Directive with others including the Water Framework Directive;

- The need for greater public involvement in flood risk management planning;

- Constrained public finances in many countries;

- Response to international programmes such as the UN International Strategy for Disaster Reduction $(\mathrm{UNISDR})^{7}$ and the Hyogo Framework for Action (HFA).

\subsection{The complexity of decision making}

The interaction of all these factors confirms that flood risk management is a "wicked problem". It has been recognised that flood risk management requires the use of a "portfolio" of measures rather than a single solution (Office of Science and Technology 2004, Samuels et al. 2006). These measures will include the

\footnotetext{
${ }^{7}$ For UNISDR and HFA see http://www.unisdr.org/
} 
traditional approaches of providing defences, increasing flow capacity and providing flood warnings during an event. However, more is needed. In Article 7, the Floods Directive $(E C, 2007)$ requires that flood risk management plans should consider many aspects.

"Flood risk management plans shall take into account relevant aspects such as costs and benefits, flood extent and flood conveyance routes and areas which have the potential to retain flood water, such as natural floodplains, the environmental objectives of Article 4 of Directive 2000/60/EC, soil and water management, spatial planning, land use, nature conservation, navigation and port infrastructure.

Flood risk management plans shall address all aspects of flood risk management focusing on prevention, protection, preparedness, including flood forecasts and early warning systems and taking into account the characteristics of the particular river basin or sub-basin. Flood risk management plans may also include the promotion of sustainable land use practices, improvement of water retention as well as the controlled flooding of certain areas in the case of a flood event."

Economic and social development (physical, governance, institutional, social, etc) has become so complex that the occurrence of an extreme produces a shock to the ambient state leading to unforeseen and problematic consequences and impacts. Thus we arrive at a key challenge: how to make robust decisions given the uncertainty in future conditions? Moreover, past solutions may not be appropriate. Land exposed to flood hazard may need to be abandoned or settlements moved and land-use changed; life in urban areas might be designed to storm water flowing in "blue routes" above ground rather than below, and existing buildings and infrastructure may need adaptation.

Decisions taken now have inter-generational consequences and sustainability requires us to seek out a noregrets route to meeting our needs without compromising the ability of future generations to meet their needs. One method under research for addressing this is that of "real options" (Woodward et al. 2011).

\subsection{A personal view on R\&D priorities}

\subsubsection{Preamble}

In all flood risk management research programmes there is some form of categorisation to facilitate the identification of individual projects which meet the overall needs of the funders or the end-user of the research outcomes. For example, the UK Flood and Coastal Erosion Risk Management Research Strategy contains three broad areas (See Section 2.2 above) which respond to the business needs in particular of the Environment Agency.

My own set of research needs as discussed below uses the flood risk management cycle (Samuels et al. 2008, see figure 1), and I have coupled this with the need for adaptation to climate change. The general areas are:

- Improving our ability to make long-term plans and explore options for flood risk management;

- Support the response to, and the management of, flood emergencies;

- Support the adaptation of society to inevitable long-term changes in flood risk. 


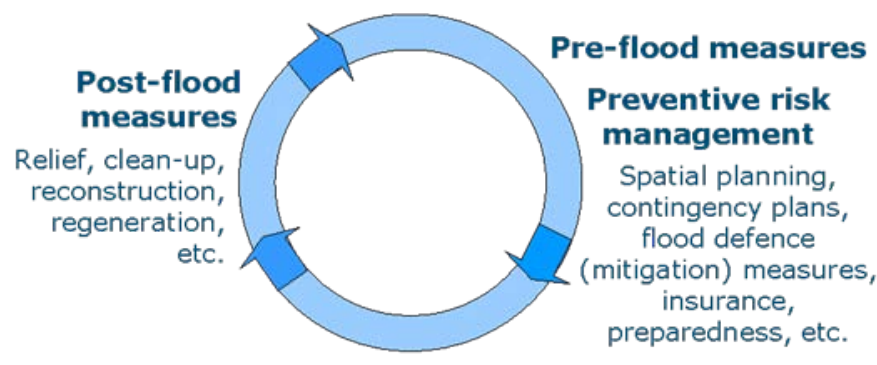

Flood event measures

Real time risk management

Forecasting and warning, reservoir control, evacuation, rescue, etc.

Figure 1: The risk management cycle

I hope these general areas are sufficiently generic to encapsulate the actions needed for flood risk management whatever the social and economic factors are in different countries; however, I would first like to identify the importance of data in supporting this R\&D.

\subsubsection{Data}

Access to reliable data is the foundation for advancing understanding in flood risk management. This applies to all aspects of the research including the hydro-meteorology of floods and the socio-economic assessment of the consequence of flooding.

As we move into a future where the assumption of stationarity in climatic conditions no longer can be made, long-term datasets are crucial for understanding and quantifying the effects of past change in climate and catchment conditions. The need for improved data was the focus of a workshop convened in January 2011 by the ACQWA project at the request of the EC Research and Innovation Directorate (Beniston et al. 2012). Institutional, organisational and access issues for flood risk management R\&D arising in currently held data and that being collected include:

- Recognising the long-term value of records as opposed to immediate value for example for legislative compliance or facility operation;

- Digitisation and accessibility to historic meteorological records;

- Measurement of river flows in extreme events

- Precipitation measurement in remote areas;

- Consistent aggregation of datasets for physical parameters and the economic and social impacts of floods.

In addition new and emerging technologies may change the way in which data is collected and provide opportunities for new types of data to be available for analysis.

\subsubsection{Long-term planning and option assessment}

Research on extreme floods needs to be set in a multi-hazard framework for several risk sources, which may be coincidental, conjoint or cascading, taking a "whole systems" approach to the physical, environmental, ecological and social systems, and their interdependencies and interconnectivities. 
A difficulty with public involvement in long-term planning is that the typical time-scale between the occurrence of major floods and the devastation caused may be two or more generations and thus the impacts lie outside the scope of life-time memory of much of society. Moreover, natural processes that are responses to these extremes (for example morphological adjustment of rivers) may undergo step changes in response to an extreme, upsetting the apparent benign appearance of a static equilibrium to which the public has become accustomed.

An additional complication is that policy development accounts for climate change over multi-generational timescales but investment decisions cover generational (decadal) timescales. Thus scenarios are needed to explore the potential flood hazards and risks over a timescale of say 100 years, with information at the decadal timescale suitable for investment appraisal.

Scenario-based analysis of strategic flood risk management alternatives has already been researched in FLOODsite with examples from the Netherlands and the UK (Klijn et al. 2008). However, there remains considerable uncertainty with generating hydro-meteorological scenarios at the catchment scale from climate modelling output and in terms of coastal surge and wave conditions. Hence I see this as an important area for future research requiring collaboration between the meteorological community involved in climate simulation, flood hydrologists and oceanographers.

Practical advice on decadal scale information is now beginning to be provided for decision-making. For example, in England and Wales, the Environment Agency has prepared advice for use in making spatial planning decisions (Environment Agency 2011). The advice derives from the national UKCP09 climate projections ${ }^{8}$ and provides the range of allowances to use for climate impact on rainfall and mean sea level, with regional variations, decadal values and an estimate of range of the potential change. However, UKCP09 does not provide a full understanding of changes to extreme, convective rainfall at the scales needed to manage surface water flooding.

The need is urgent to improve understanding and reduce uncertainty for estimates of decadal timescale changes to floods and their impacts. This includes climate projections for short-duration extreme rainfall which are particularly relevant in risk management of impacts of extreme floods on society. In addition information is needed on the potential for change of the likelihood of sequences and combination of events. For the next decade or two greater use might also be made of past records in generating estimates of changes in flood hazards. Again the research will require collaboration between the meteorological community involved in climate simulation, flood hydrologists and oceanographers.

Better understanding is needed on the degree to which changes in the intensity of extremes can be attributed to natural variability or to anthropogenic influence on climate. Current research suggests that climatic signal in the trend in hydrological response may be discernable from natural variability within one or two decades.

In addition to climate scenarios, long term planning requires consistent scenarios for other environmental, social and economic factors. These scenarios will, of course, vary nationally allowing for different population projections, economic growth and macro-scale international governance.

Cost-benefit assessment is used widely in making decisions on flood risk management measures. This requires an assessment of the damages avoided by implementing the measures. In the first round of CRUE projects it was identified that the level of uncertainty in damage and risk estimates is about $45 \%$, hence, more research is necessary to provide statistically sound foundation of damage functions and risk estimates.

\footnotetext{
${ }^{8}$ See http://ukclimateprojections.defra.gov.uk/
} 
Research is needed on the appropriateness of traditional cost-benefit methods for the appraisal of certain non-structural flood risk measures such as spatial planning, regulation of land use, and the availability and take-up of flood insurance.

\subsubsection{Management of flood emergencies}

Over the past three decades research on radar hydrology and numerical weather prediction has led to substantial improvement in the reliability and the lead-time available from operational flood forecasting systems. Such systems are an essential component of warning of flood emergencies. The EC FP5 project EFFS has led directly to the European Flood Alert System EFAS, which now provides basin-scale probabilistic flood alerts over the whole of Europe for up to 10 days ahead (Thielen et al. 2009).

There remains much useful R\&D to be done in the forecasting of river and coastal flooding. Improved flashflood forecasting will come from the integration of high resolution numerical weather prediction with weather radar. It is still difficult to provide effective warning of short lead-time, rapid-onset flooding in urban areas and research should concentrate on developing the ability to warn at say a 12-hour time horizon combined with an estimate of uncertainty. Such improved precipitation forecasts will need to be coupled with detailed topographic models of the flow through the urban area to provide warning of so-called pluvial flooding.

Further research emphasis is needed on supporting the operational activities of the civil protection agencies during a flood emergency. Loss-of-life and evacuation models for emergency management have the potential to inform civil contingency planning and flood event management; this would assist a wider assessment of emergency plans as recommended by the ERA-NET CRUE project FIMFRAME. Likewise a better understanding and representation is needed of the inter-linkages between the flooding system and the socio-economic system that benefits from the flood defences. In particular, attention needs to be directed at potential failures of critical infrastructure that is exposed to flood hazard and the cascade of consequences so that civil contingency planning can explore the full extent of an emergency.

Another area where research is needed is in real-time detection of changes in the state of the flood defence system during an event and automatically integrating this information into flood forecasts. System changes could include failure of defence infrastructure (banks, sluices, pumps, etc) and blockage of structures by debris. Accessing real-time information on system states will assist in developing real-time risk information taking account of the changed probability of flooding and the consequences of inundation. Other papers at FLOODrisk 2012 cover the FP7 project UrbanFlood, which is making progress on this issue through integrating signals from sensors embedded in embankments into an early warning system.

\subsubsection{Exploring adaptation and resilience to floods}

Extreme floods are, by definition, experienced infrequently and thus the question arises to what extent should there be an attempt to control the extreme and to what degree physical and social infrastructure should be adaptable and designed as resilient to extreme conditions.

In any country, the appropriate mixture of measures and adaptations will depend upon the financial resources available for flood risk management and the resilience of the society to living with floods. Where resilience is poor, or the magnitude of extreme floods increases, flood emergencies may be transformed into disasters when serious disruption of the functioning of the community exceeds the ability of the society affected to cope using its own resources. 
Although in many countries the move from flood defence to flood risk management has been made in the policy domain, the consequences of this change in approach still has to work through to individuals and businesses in the communities at risk. The policy implies the need for greater public and stakeholder involvement in managing the flood risks experienced and becoming individually and collectively more resilient. I see that this leads to three main questions each of which comprises further questions.

1. What is resilience and what influences it?

- How do we characterise resilience to flooding, what indicators are appropriate to assess the effectiveness of actions to increase resilience?

- What impact will demographic changes (e.g. age, population density, occupancy rates, ethnicity, mobility etc.) have on preparedness for floods, coping with an emergency and long-term recovery?

- What are the consequences of this "privatisation" of risks for social vulnerability and the ability of individuals and communities to accept and cope with flood risk?

2. How do we best communicate on flood risk and involve stakeholders in flood risk management?

- How do we make flood risk management become a real part of citizen's lives and for businesses, not just for policy-makers and professionals?

- What are the best means of communicating different types of flood risk information for pre-flood planning or during an emergency? (How can citizens be concerned about floods if they have no experience in their area?)

- Should we communicate emphasising the concept "danger" or that of "safety" from floods and how does risk perception change with citizen's age?

3. How will this change in approach work?

- How do we encourage people at risk from flooding to undertake private precautionary measures?

- How best can we ensure that individuals and businesses respond appropriately to flood warnings?

- What influence will any greater expectation or reliance on individual risk management have on civil contingency planning?

An important issue in all countries and communities affected by flooding is the health impacts of flooding. Flood water can carry and spread pollutants and pathogens whose influence can last for many months after the flood has receded. Improvements in knowledge and means of mitigation of the negative effects of flooding on health will lead to faster recovery from flooding and thus improve resilience.

In accepting that some flooding will occur, the question arises on how the communities and businesses affected can be best supported to recover from the consequences of inundation. Comparatively little research has been done on flood recovery; further R\&D could be done on social factors to facilitate recovery and possibly also on means of restoring physical damage.

\section{Concluding remarks}

In the most simple terms flood risk management is about keeping flood water away from people or people away from flood water. This requires risk management measures and actions both before a flood and during a flood emergency. Nevertheless, it is unrealistic to expect that flood risks can be eliminated and so future flood risk management must include a degree of adaption of society to living with the flood hazard.

Past research on flood risk management has brought real advances in knowledge and understanding which have been taken up into practice and have shaped changes in policy. However, looking to the future 
indicates that flood risks are set to increase driven by changes in climate, population, demographics and patterns of land use and settlement. Our management of floods and flood risks must respond to these pressures in a sustainable way which does not prejudice the ability of future generations to meet their own needs; again this points to adaptation as a key strategy.

In this paper I have suggested some areas for research and development which I consider could improve our ability to understand, manage and adapt to flood risks. Others will want to add their own priorities for R\&D and we must always be prepared to exploit technological development elsewhere in improving flood risk management. Whatever research is done it is crucial that there is a clear plan and commitment for the research outcomes to be brought into practice. As many flood risk management measures are undertaken by the state, this will require the flood management agencies to plan to integrate the research findings into their own policies and implement them in practice.

\section{Acknowledgements}

Some of the research topics I have suggested in this paper have arisen in discussion at meetings I have attended with the support of the EC Directorates for the Environment and for Research and Innovation; in particular Thematic Workshops in 2010 and 2012 of the Floods Directive Working Group F and of two meetings of water-related Framework Projects in 2011.

I would like to thank my colleague Jonathan Simm for his comments upon a draft of this paper.

\section{References}

Ashton, V., Aziz, H., Keith, S. and Smith, T. (2003) Review of EU Flood R\&D Projects, The University of Birmingham. Group management project on the MSc. Water resources technology and management course.

Beniston, M., Stoffel, M., Harding, R., Kernan, M., Ludwig, R., Moors, E., Samuels, P. and Tockner, K. (2012) 'Obstacles to data access for research related to climate and water: Implications for science and EU policy-making', Environmental Science and Policy, 17 (0), pp. 41-48.

EC (2007), Vol. L 288/27 Official Journal of the European Union, Brussels.

Environment Agency (2011) Adapting to Climate Change: Advice for Flood and Coastal Erosion Risk Management Authorities, Environment Agency, Bristol

Harvey, G., Thorne, C., Cheng, X., Evans, E., J.D. Simm, S.H. and Wang, Y. (2009) 'Qualitative analysis of future flood risk in the Taihu Basin, China', Journal of Flood Risk Management, 2 (2), pp. 85-100.

Klijn, F., De Bruijn, K., Mc Gahey, C., Mens, M. and Wolfert, H. (2008a) Long-term strategies for flood risk management: scenario definition and strategy design, FLOODsite Report T14-08-01. www.floodsite.net

Klijn, F., Samuels, P. and Van Os, A. (2008b) 'Towards flood risk management in the EU: State of affairs with examples from various European countries', International Journal of River Basin Management, 6 (4), pp. 307-321.

Knight, D.W., Mc Gahey, C., Lamb, R. and Samuels, P.G. (2010) Practical Channel Hydraulics, CRC Press, London.

Knight, D.W. and Sellin, R.H.J. (1987) 'The SERC Flood Channel Facility', Water and Environment Journal, 1 (2), pp. 198-204. 
Mc Gahey, C., Samuels, P.G., Knight, D.W. and O'Hare, M.T. (2008) 'Estimating river flow capacity in practice', Journal of Flood Risk Management, 1 (1), pp. 23-33.

Ministry of Agriculture Fisheries and Food (1992) Flood and Coastal Defence Research and Development: Report of the Advisory Committee, MAFF Publications, London

Ministry of Agriculture Fisheries and Food (1999) Flood and Coastal Defence Research and Development: Report of the Advisory Committee, MAFF London

Office of Science and Technology (2004) Future Flooding Volume 1: Future risks and their drivers, HMSO, London

Organisation for Economic Co-operation and Development (1993) The measurement of scientific and technological activities : proposed standard practice for surveys of research and experimental development : Frascati manual, OECD Publications and Information Center, Washington DC.

Pender, G. (2006) 'Briefing: Introducing the Flood Risk Management Research Consortium', Proceedings of Institution of Civil Engineers, Water Management 159 (WM1), pp. 3-8.

Penning-Rowsell, E. (2005) An Independent review of the Defra/ EA research and development joint programme in flood and coastal erosion risk management, Defra, London

Quevauviller, P. (2011) 'WFD River Basin Management Planning in the Context of Climate Change Adaptation - Policy and Research Trends', European Water, 34, pp. 19-25.

Rittel, H. and Webber, M. (1973) 'Dilemmas in a General Theory of Planning', Policy Sciences, 4, pp. 155169.

Samuels, P.G., Klijn, F. and Dijkman, J. (2006) 'An Analysis of the Current Practice of Policies on River Flood Risk Management in Different Countries', Irrigation and Drainage, 55, pp. S141-156.

Samuels, P.G., Morris, M.W., Creutin, J.-D., Sayers, P.B., Kortenhaus, A., Klijn, F., Mosselman, E., Os, A.v. and Schanze, J. (2008) 'Advances in flood risk management from the FLOODsite project', Flood Risk Management: Research and Practice (FLOODrisk 2008), Oxford,

Shiono, K. and Knight, D.W. (1991) 'Turbulent open-channel flows with variable depth across the channel', Journal of Fluid Mechanics, 222, pp. 617-646.

Simm, J., Wallis, M., Smith, P., Tourment, R., Veylon, G., Denaud, Y., Durand, E., McVicker, J. and HershBurdick, R. (2012) 'The significance of failure modes in the design and management of levees - a perspective from the International Levee Handbook team', FLOODrisk 2012, Rotterdam,Novermber 2012.

Thielen, J., Bartholmes, J., Ramos, M.H. and de Roo, A. (2009) 'The European Flood Alert System Part 1: Concept and development', Hydrol. Earth Syst. Sci., 13 (2), pp. 125-140.

Woodward, M., Gouldby, B., Kapelan, Z., Khu, S.T. and Townend, I. (2011) 'Real Options in flood risk management decision making', Journal of Flood Risk Management, 4 (4), pp. 339-349. 